\title{
O DIREITO FUNDAMENTAL DOS SERVIDORES PÚBLICOS À NEGOCIAÇÃO COLETIVA EM FACE DA CONVENÇÃO 151 DA OIT
}

\author{
Renato de Almeida Oliveira Muçouçah* \\ Felipe José Nunes Rocha**
}

SUMÁRIO: Introdução; 2 Negociação Coletiva de Trabalbo na Administração Pública e Breve Perspectiva Comparada; 3 As Convenções da OIT enquanto Tratados Internacionais de Direitos Humanos; 4 A Convenção 151 da OIT e o Direito Fundamental dos Trabalbadores da Administração Pública à Negociação Coletiva; 5 Conclusão; Referências.

RESUMO: Este artigo tem por objetivo analisar a ratificação da Convenção 151 da OIT pelo Brasil, partindo de uma análise acerca da possibilidade de se considerar os direitos previstos em tal tratado como direitos fundamentais, após a sua incorporação pelo ordenamento jurídico brasileiro. Além disso, pretende-se analisar, de modo mais específico, o direito à negociação coletiva dos trabalhadores da Administração Pública, que é previsto nessa Convenção, a partir do modo como tal instituto vem sendo tratado pelo Estado brasileiro, e também quais seriam os efeitos do reconhecimento da negociação coletiva como um direito fundamental. Para tanto, buscou-se o estudo hipotético-dedutivo das questões existentes nas lacunas do direito brasileiro, via análise dedutiva de bibliografia especializada e as hipóteses de resposta apresentadas. Também foram analisados julgados que guardam pertinência temática com o artigo, para que se chegasse a conclusões em defesa da fundamentalidade do direito em exame e maneiras de dar-lhe efetividade.

PALAVRAS-CHAVE: Administração pública; Cláusulas negociais; Direitos fundamentais; Negociação coletiva; OIT.

\section{THE BASIC RIGHT OF CIVIL SERVANTS TO COLLECTIVE NEGOTIATIONS IN THE WAKE OF ILO CONVENTION 151}

ABSTRACT: The signing of Convention 151 of the International Labor Organization by Brazil is discussed. The analysis comprises the possibility of considering the rights

\footnotetext{
Doutor em Direito do Trabalho Universidade de São Paulo (USP); Pós-Doutor em Direito pela Universidade Federal do Maranhão (UFMA); Docente efetivo na Graduação e no Programa de Pós-graduação em Direito Mestrado da Faculdade de Direito da Universidade Federal de Uberlândia (UFU); Docente colaborador no Programa de Pós-graduação em Direito da Universidade Federal do Maranhão (UFMA), Brasil;

E-mail: mucoucah@usp.br

** Mestrando no Programa de Pós-graduação em Direito pela Universidade Federal do Maranhão(UFMA); Advogado e Docente Universitário.
} 
in the treaty as basic after their incorporation within the Brazilian juridical system. The right to collective negotiation by civil servants, included in the Convention, the civil servant statute and its effects as basic rights when acknowledged are also specifically debated. A hypothetic and deductive analysis of issues lacking in Brazilian law are endeavored through specialized bibliography and responses to the forwarded hypotheses. Several cases on the theme are also investigated so that one might conclude on the basic fundamental rights under discussion and the manner they should be effective.

KEY WORDS: ILO; Collective negotiation; Public administration; Basic rights; Negotiated terms.

\section{EL DERECHO FUNDAMENTAL DE LOS SERVIDORES PÚBLICOS DE NEGOCIACIÓN COLECTIVA DESDE EL CONVENIO 151 DE OIT}

RESUMEN: Este artículo tiene como objetivo examinar la ratificación del Convenio 151 de la OIT en Brasil, a partir de un análisis de la posibilidad de considerar los derechos previstos en un tratado como los derechos fundamentales, después de su incorporación en el ordenamiento jurídico brasileño. También tiene como objetivo examinar, más específicamente, el derecho a la negociación colectiva de los trabajadores del sector público, que se establece en dicho Convenio, desde cómo este instituto está siendo abordado por Brasil, y también lo que sería el reconocimiento de los efectos la negociación colectiva como un derecho fundamental. Con este fin, hemos tratado el estudio hipotético-deductivo de los problemas existentes en las lagunas de la legislación brasileña, a través de análisis deductivo de la bibliografía pertinente y las respuestas alternativas previstas. Fueron también analizados juzgado que espera relevancia el tema con el artículo, para llegar a las conclusiones en defensa de fundamentalidad del derecho de que se trate y las maneras de darle efectividad.

PALABRAS-CLAVE: Administración pública; Cláusulas de negociación; Derechos fundamentales; Negociación colectiva; OIT.

\section{INTRODUÇÃO}

A Constituição Federal de 1988, reconhecendo a necessidade de se conferir um tratamento isonômico entre os trabalhadores da iniciativa privada e aqueles da Administração Pública, assegurou a estes últimos vários dos direitos fundamentais 
que, em outros momentos históricos, foram garantidos apenas aos empregados das empresas privadas, a exemplo dos direitos à greve e à sindicalização.

A formação do Estado brasileiro carrega consigo um viés autoritário. Os períodos democráticos do país foram vividos apenas entre 1946 e 1964, e de 1985 até a atualidade. Após a independência do Brasil, quando houve a real necessidade de criar-se um aparato burocrático com quadros de boa formação intelectual, o Império fez a opção por investir na formação universitária, especialmente em Direito (nas cidades de São Paulo e Olinda). Em um país em que a maioria da população era analfabeta, pouco se investiu na formação básica, pois o Estado necessitava de certa elite, profissionalmente qualificada, para atuar no serviço público.

Ainda no Império a sindicalização restou proibida, vez que era considerada nociva ao interesse público. Durante a República Velha, que trouxe ao país a Constituição dos Estados Unidos do Brasil, de 1891, não havia menção ao sindicalismo: revogou-se a anterior proibição constitucional e silenciou-se a respeito do tema. Em não se garantindo direito, mas não sendo expressamente vedada a sindicalização e a greve, passou-se a uma fase de tolerância no plano legal (embora não necessariamente tal tolerância se tenha visto no plano fático). A lacuna permitiu que algumas décadas depois, máxime com a chegada dos imigrantes europeus, movimentos sindicais ganhassem caráter não só jurídico, mas também político. Somente a partir da década de 1930 as Constituições começaram a prever direitos de natureza sindical, incluindo a negociação coletiva. O ápice desta caminhada democrática foi a Constituição Federal de 1988 e a construção social do direito a partir daí decorrente.

Entretanto, apesar de a Carta Magna ter trazido avanços significativos em vários aspectos, o ordenamento jurídico pátrio ainda mantém tratamento discriminatório entre os trabalhadores do setor privado e os servidores públicos. É o que ocorre, por exemplo, em relação ao direito à negociação coletiva, taxativamente previsto para o setor privado como garantia fundamental (artigo $8^{\circ}$, VI, Constituição Federal), mas sem definição alguma no que concerne à Administração Pública.

Para efeito de compreensão, toda vez que se mencionar Administração Pública no presente texto estar-se-á a mencionar a Administração Pública direta (pessoas jurídicas de direito público interno, como União, Estados e Municípios, bem como Ministérios, Secretarias e demais órgãos diretamente vinculados aos entes federados). Também se compreende, para efeitos de Administração Pública 
nesse artigo, as Autarquias e Fundações de direito público. É mister estabelecer tal diferenciação, pois na Administração Pública indireta encontram-se as Autarquias e Fundações, tanto de direito público quanto privado. Ademais, encontram-se também as sociedades de economia mista e as empresas públicas, que se constituem sob o formato de pessoas jurídicas de direito privado. A tais entes, até mesmo por terem seus trabalhadores regidos pela Consolidação das Leis do Trabalho, a negociação coletiva de trabalho e os diplomas negociais já são inquestionavelmente admitidos.

No âmbito do sindicalismo, que surgiu em razão da histórica vulnerabilidade e hipossuficiência do trabalhador em face do empregador, a negociação coletiva emerge como um importante instituto voltado para assegurar aos trabalhadores do setor privado a capacidade de discutir e apresentar suas reivindicações à classe patronal, para que mínimas condições de dignidade pessoal e social pudessem ser concretizadas e atendidas. Por outro lado, ainda que argumentar-se que muitos dos trabalhadores da Administração Pública só possam ser demitidos em caso de cometimento de infração disciplinar e após a instauração e conclusão de processo administrativo disciplinar - o que lhes confere estabilidade incomparável àquela garantida na iniciativa privada, ex vi do artigo 41 da Constituição Federal - mesmo assim não estará afastada a sua hipossuficiência diante das instituições públicas paras as quais trabalham e que os remuneram.

Os servidores públicos, além de estarem sujeitos às ordens e diretivas de suas chefias, ainda lidam com uma dada peculiaridade, que diz respeito ao fato de trabalharem para quem define as "regras do jogo" unilateralmente, que é o Estado, sob certo contexto econômico mundial em que cada vez mais direitos de empregados e de servidores públicos são vistos como regalias.

A negociação coletiva de trabalho poderia - ou poderá - funcionar como importante instrumento de pacificação social e de pacto político diante das peculiaridades da Administração Pública. Apesar de o Estado brasileiro ainda não ter previsão específica acerca da possibilidade de aplicar-se a negociação coletiva em âmbito público, houve, recentemente, um importante avanço, que corresponde ao fato de o Brasil ter assinado e ratificado a Convenção 151 da Organização Internacional do Trabalho (OIT), por meio da qual o Estado se compromete a assegurar o direito dos empregados e servidores públicos à negociação coletiva e, com base nessa mesma Convenção, institui normas para o exercício desse direito fundamental, que é corolário da liberdade sindical. 
Há objeções, porém, quanto à aplicação e legalidade desse dispositivo. Em se tratando de Administração Pública, os direitos dos servidores públicos são tidos como gastos que o Estado deveria deixar de ter na medida do possível, até mesmo para atender aos ditames da Lei Complementar 101/2000 (Lei de Responsabilidade Fiscal) que, embora traga limites claros ao administrador para o bom emprego do dinheiro público, certas vezes serve como escusa para que a Administração sistematicamente negue a valorização de seus quadros (e a prestação com qualidade de serviços), alegando aumento de despesas, as quais comprometerão os cofres públicos acima dos limites fixados nesse plano normativo.

Ademais, sustenta-se que o Estado não possui a mesma liberdade dos particulares para assumir compromissos negociais, vez que aumentos de despesa - ao menos no sistema brasileiro - necessitam da iniciativa do chefe de um dos Poderes e a aprovação pelo outro. Bom exemplo é o dos servidores públicos do Executivo: direito à sindicalização e à greve são garantidos, mas a negociação coletiva pode ou não ser viável sob o prisma jurídico porque o chefe desse Poder teria de apresentar projeto de lei, que dependerá da concordância de outro Poder (no caso, o Legislativo). No caso do Poder Judiciário, por exemplo, haverá necessidade de projeto de lei por parte do Presidente do Supremo Tribunal Federal, a ser aprovado pelo Poder Legislativo e sancionado pelo Executivo. Logo, como seria possível estabelecer negociação coletiva com representantes dos trabalhadores que servem a um dos Poderes, se isso dependerá da concordância de outro(s)?

É possível observar sem muitas dificuldades que a Constituição Federal, nesse aspecto, é falha: prevê o direito à sindicalização do servidor público civil e até mesmo o direito à greve (a qual, no setor privado, é precedida pela negociação coletiva, já que a greve é uma das poucas fórmulas de autotutela de direito existentes no ordenamento pátrio). Logo, pretende-se examinar se há meios possíveis para que se institua a negociação coletiva na Administração Pública brasileira, ainda que com todas as restrições que doutrina e jurisprudência apontam.

Por ser um tema cujo estudo demanda conhecimentos de Direito Constitucional, Direito Internacional, Direito do Trabalho e Direito Administrativo, o tratamento dedutivo da pesquisa bibliográfica, que analisará obras acerca do tema proposto, também contará com a análise indutiva de julgados e posições do Supremo Tribunal Federal e do Tribunal Superior do Trabalho acerca de assuntos relacionados ao tema estudado, de maneira a apresentar respostas quanto às lacunas encontradas em teste dedutivo de hipóteses (método hipotético-dedutivo). 


\section{NEGOCIAÇÃO COLETIVA DE TRABALHO NA ADMINISTRAÇÃO PÚBLICA E BREVE PERSPECTIVA COMPARADA}

Analisando-se de modo específico a Convenção 151 da OIT, é mister salientar a relevância e as consequências de se reconhecer a fundamentalidade do direito à negociação coletiva na esfera da Administração Pública. Para tanto, convém, inicialmente, tecer algumas considerações sobre o instituto da negociação coletiva e a sua compatibilidade com o regime de trabalho da Administração Pública.

José Augusto Rodrigues Pinto explica que

[...] a negociação coletiva deve ser entendida como o complexo de entendimentos entre representações de categorias de trabalhadores e empresas, ou suas representações, para estabelecer condições gerais de trabalho destinadas a regular as relações individuais entre seus integrantes ou solucionar outras questões que estejam perturbando a execução normal dos contratos ${ }^{1}$.

É importante verificar a conceituação de negociação coletiva prevista no artigo $2^{\circ}$ da Convenção 154 da Organização Internacional do Trabalho, diploma este que foi estabelecido com o objetivo de incentivar a negociação coletiva. $\mathrm{O}$ Brasil ratificou a mencionada Convenção em setembro de 1994, com a promulgação do Decreto 1.256, de 29 de setembro daquele ano ${ }^{2}$. No bojo de seu texto há um conceito amplo de negociação coletiva a também envolver, como atores sociais, a Administração e os servidores públicos.

A negociação coletiva, por envolver atores que representam coletivamente os dois polos da relação trabalhista e, dessa maneira, poder versar sobre várias questões inerentes aos direitos dos trabalhadores, constitui-se em um importante mecanismo para possibilitar a convivência amistosa em ambientes marcados por conflitos inerentes à relação entre capital e trabalho, ainda que o representante do "capital", nesse caso, seja o Estado - que, ao menos em tese, não tem objetivos lucrativos.

\footnotetext{
PINTO, José Augusto Rodrigues. Direito Sindical e Coletivo do Trabalho. São Paulo: LTr, 1998, p. 168.

2 É o que se verifica, in verbis: "art. $2^{\circ}$ Para efeito da presente Convenção, a expressão 'negociação coletiva' compreende todas as negociações que tenham lugar entre, de uma parte, um empregador, um grupo de empregadores ou uma organização ou várias organizações de empregadores, e, de outra parte, uma ou várias organizações de trabalhadores, com fim de: a) fixar as condições de trabalho e emprego; ou b) regular as relações entre empregadores e trabalhadores; ou c) regular as relações entre os empregadores ou suas organizações e uma ou várias organizações de trabalhadores, ou alcançar todos estes objetivos de uma só vez". In: BRASIL. Decreto 1.256, de 29 de setembro de 1994. Diário Oficial da União, Brasília, v. 132, n. 188, 30 set. 1994. Seção 1, p. 14823.
} 
Em outras palavras, como afirma Luciana Bullamah Stoll, a negociação coletiva é o processo dinâmico "voltado ao atingimento do ponto de equilíbrio entre interesses divergentes visando satisfazer, transitoriamente, as necessidades presentes dos grupos de trabalhadores e de equalizar os custos de produção"3. Em grande parte dos países do mundo a relação entre servidores públicos e Estado, seja em se tratando de Administração direta ou indireta, começa a ser contratualizada ou privatizada, no sentido de igualar-se às regras da negociação coletiva no setor privado. A Itália é, nesse sentido, um bom exemplo. Até meados da década de 1990 entendia-se que a relação do servidor com a Administração tinha natureza dúplice: uma relação orgânica, hierárquica, e também uma relação de serviço, que deveria ter suas fontes no direito administrativo ${ }^{4}$.

Iniciou-se na Itália, todavia, um movimento de contratualidade (ou privatização) nas relações entre o servidor e a Administração Pública. A rigor, o termo contratualidade ora relatado se refere à mudança na disciplina da relação entre Estado e servidor, que passa a assemelhar-se àquela do setor privado; por essa razão, aliás, começa-se a firmar a tese de que há um contrato entre ente público e seus trabalhadores, o que deixa de qualificar tal relação jurídico-trabalhista meramente como ato administrativo. Com o objetivo de tornar o Estado mais eficiente, estimular o aprimoramento profissional dos trabalhadores da Administração Pública - inclusive para tomar parte na União Europeia - os italianos, por meio de reformas legislativas na década de 1980, passaram a aplicar não tanto o direito administrativo, e sim o direito do trabalho aos seus servidores, até mesmo para que estes tivessem a chance de angariar conquistas como aquelas dos empregados privados, pela própria força dos trabalhadores em suas lutas sindicais democráticas. Esse movimento, no entanto, vem sendo freado aos poucos 5 .

Em 2001 os servidores passaram a ter direito mais amplo à negociação coletiva com o Estado, que antes era fragmentada e setorizada: o ente público, representado pela ARAN (Agenzia per la rappresentanza negoziale delle pubbliche amministrazioni), passou a negociar diretamente, com os diversos entes sindicais de servidores públicos, questões específicas do funcionalismo público, vez que a relação entre servidor e Administração continua a ter natureza especial. No entanto, em tudo o que for compatível com o erário público (que já deverá traçar metas

\footnotetext{
STOLL, Luciana Bullamah. Negociação coletiva no setor público. São Paulo: LTr, 2007, p. 26.

4 GHERA, Edoardo. Diritto del Lavoro. 17. ed. Bari: Cacucci, 2012, p. 277.

5 GHERA, Edoardo, op. cit., p. 278-280.
} 
orçamentárias para possíveis acordos, estabelecidos por meio da ARAN), o direito do trabalho, com as ressalvas do direito administrativo, é o conjunto de normas que deverá (ou deveria) reger primordialmente as relações de trabalho na Administração Pública, especialmente para garantir aos servidores certos direitos antes só garantidos aos particulares ${ }^{6}$.

Esse movimento tem origem no final da década de 1960: o funcionalismo público italiano que, por ser fragmentado e heterogêneo em seus interesses, pouco conseguia do Estado, passou a contar com os mesmos mecanismos de negociação coletiva já previstos para o setor privado. A partir da Lei 93/1983 os diplomas coletivos do funcionalismo público passaram a alcançar toda a Administração, e não apenas pequenos segmentos desta. Essa tendência, denominada como a contratualidade da relação jurídico-administrativa, por permitir a supremacia do negociado sobre o legislado na Administração, nos anos noventa acabou por ser qualificada como privatização do serviço público, no sentido de conferir ao funcionalismo apenas as previsões mínimas da lei, e uma redução de direitos quase sempre avalizada pelos sindicatos.

A partir da reforma liberal promovida pela Lei Biagi, com o incentivo do governo Berlusconi, a partir de 2003 (culminando com a Lei 133/2008), passouse a controlar cada vez mais os limites da negociação coletiva de trabalho com a Administração Pública, difundindo-se uma visão empresarial do Estado - mais pelas leis em geral que pelos diplomas coletivos. Os governos italianos perceberam que a negociação coletiva, ainda que "privatizasse" em parte a Administração Pública, possuía condições de unificar os mundos do trabalho público e privado, que o Estado tenta separar pela regulação administrativa. A expressão mais recente de tentar formar a Administração como entidade empresarial deu-se pela Lei 183/2014, em que pese a rejeição demonstrada pelos sindicatos dos servidores públicos ${ }^{7}$.

$\mathrm{Na}$ Espanha, a experiência relatada foi admitida por Franco ainda no início da década de 1960, concebendo-se a contratação, pela Administração, de pessoal tanto com regime administrativo quanto sob regime particular. Seria apenas uma técnica de gestão dos recursos humanos, idêntico truísmo visto no Brasil três décadas depois. Presumia-se maior agilidade ao Estado, inclusive sem garantia de estabilidade, quando se contratava com base no Estatuto dos Trabalhadores (no

SCOGNAMIGLIO, Renato. Diritto del lavoro. 2. ed. Bari: Laterza, 2005, p. 85-89.

7 CARINCI, Franco et al. Derecho del Trabajo: el derecho sindical. Trad. José Antonio Fernández Avilés. 6. ed. Granada: Comares, 2015. v. 1, p. 310-317. 
Brasil há que se recordar: o regime privado, sem estabilidade - e que admite até mesmo denúncia vazia do contrato de emprego - é adotado nas empresas públicas e sociedades de economia mista que explorem a atividade econômica). $\mathrm{O}$ artigo $4^{\mathrm{o}}$, c, do Estatuto dos Trabalhadores (ET), estabelece que todo empregado possui direito à negociação coletiva ${ }^{8}$.

Os servidores públicos espanhóis, na atualidade, têm seu trabalho regido pelo Estatuto Básico do Servidor Público (EBEP); tal diploma normativo já prevê expressamente o direito de sindicalização dos servidores como efetivo direito à negociação coletiva. Mais ainda: prevê a existência de representantes dos servidores (como nos comitês de empresa) e participação institucional dos estatutários nos locais de trabalho. Determinados direitos previstos aos trabalhadores em geral incluindo Convenções e Tratados Internacionais - devem ser regulamentados para serem aplicados aos servidores públicos da Espanha.

Não bastassem tais previsões, o EBEP se propõe a admitir, como fonte subsidiária de direito, tudo que contiver o Estatuto dos Trabalhadores, dirigido ao setor privado. Dessa forma, ainda que porventura haja má vontade por parte da Administração, sindicatos do setor privado (desde que representativos de parcela dos servidores, conforme percentuais legalmente fixados) poderão negociar interesses dos servidores públicos ${ }^{9}$; até mesmo planos salariais e quadros de carreira para o funcionalismo público podem ser estabelecidos via negociação coletiva.

Parcela minoritária da doutrina espanhola, porém, sustenta o que no Brasil se tem como regra: a Constituição não permite nem proíbe a negociação coletiva dos trabalhadores com a Administração. Tanto no Brasil como na Espanha existe o reconhecimento constitucional do direito à sindicalização na Administração como direito fundamental, mas não se reconhece direito de reivindicar negociação coletiva; em outras palavras, o direito de associação toma-se a "finalidade", e não um "meio" de conquista de direitos (e qual a função mais importante de um sindicato, senão entabular negociações coletivas?).

Houve a tentativa de se reproduzir, no Brasil, experiências jurídicas como a espanhola, acima narrada, embora sem sucesso: trata-se da figura do empregado público. $\mathrm{O}$ Brasil, tentando imprimir à economia e às funções estatais um modelo de viés liberal, observou-se a existência da dualidade de regimes na Administração,

\footnotetext{
8 ALONSO OLEA, Manuel. Derecho del Trabajo. Atualiz. Maria Emilia Casas Baamonde. 26. ed. Madrid: Civitas, 2009, p. 131-136.

9 ALOSO OLEA, op. cit., p. 757-767.
} 
ou seja, o servidor estatutário e o celetista. Este último desenvolveria contratos mais dinâmicos - e menos seguros para o trabalhador - com a Administração. Hoje, porém, a regra é a do regime administrativo (ou estatutário) para servidores públicos quanto às carreiras de Estado, mas ainda na atualidade há diversos municípios que não possuem Estatuto para seus servidores. Diante da ausência de regramento específico para tais servidores, deve a Administração valer-se da CLT e, por consequiência, da negociação coletiva com esses trabalhadores ${ }^{10}$.

No Brasil e na Espanha, as Cortes Constitucionais já trouxeram soluções díspares ao problema: no país sul-americano, consideraram incompatível o sistema estatutário, que obedece aos princípios da legalidade e da reserva legal, dentre outros, com o celetista, que admite a negociação coletiva. Já o país ibérico considera a negociação coletiva como corolário da liberdade sindical prevista na Constituição, além de interpretar a palavra trabalhadores, prevista no ET (que no Brasil existe no próprio artigo $7^{\circ} \mathrm{da}$ Carta Magna), de forma genérica e que também se dirige aos trabalhadores da Administração, mesmo que estatutários, por ser norma subsidiária ao Estatuto dos Trabalhadores, consoante asseverado alhures ${ }^{11}$.

Desde 1988 os estudiosos, ao debruçarem-se sobre o tema da negociação coletiva quanto aos servidores públicos, apontam diversas impossibilidades para concretizá-la. Um argumento recorrente é a supremacia do interesse público: essa questão remete com frequência, aliás, ao chamado "regime unilateralista" praticado pelo Estado. Exemplifica-se a afirmação com a tutela dos direitos e deveres, por exemplo, dos servidores públicos civis da União: encontram-se estabelecidos em um diploma normativo, qual seja, a Lei 8.112/1990, principal instrumento aplicável às relações estatutárias ${ }^{12}$. É o Estado que dita, de maneira unilateral, o que concederá ou não aos seus servidores.

Amauri Mascaro Nascimento denomina tal fenômeno como monismo estatal, ao contrário do pluralismo de fontes que existiria no Direito do Trabalho aplicado ao setor privado ${ }^{13}$. Para esse autor, há as normas estatais e as não estatais, como os diplomas negociais coletivos (Acordo e Convenção), além dos usos e costumes. Nenhuma norma aplicável aos servidores públicos teria origem em órgão não estatal, o que tornaria os regimes estatutário e celetista incompatíveis entre si.

${ }_{10}$ DELGADO, Maurício Godinho. Curso de Direito do Trabalho. 14. ed. São Paulo: LTr, 2015, p. 466-467.

${ }^{11}$ PAES, Arnaldo Boson. Negociação coletiva na função pública: abordagem crítica do modelo brasileiro a partir do paradigma espanhol. São Paulo: LTr, 2013, p. 166-175.

12 BRASIL. Lei 8.112, de 11 de dezembro de 1990. Diário Oficial da União, Brasília, v. 128, n. 237, 12 dez. 1990. Seção 1, p. 23935-23946.

13 NASCIMENTO, Amauri Mascaro. Ordenamento jurídico trabalhista. São Paulo: LTr, 2013, p. 159. 
Diversa, porém - e que parece mais escorreita - é a posição de Everaldo Gaspar Lopes de Andrade, para o qual não se pode tecer essa divisão binária na pósmodernidade. A Espanha e a Itália, por exemplo, já produzem diplomas negociais coletivos tripartites, ou seja, com a presença de empregadores e empregados, mediados pelo Estado, que também faz valer seus interesses ${ }^{14}$. Não sem motivos é que, de tempos para cá, alguns países - sobretudo europeus - têm estabelecido normas aplicáveis de forma transnacional, vez que o capital e a força humana de emprego foram transnacionalizados e, em grande medida, homogeneizados.

A globalização do capital, do trabalho e também das formas de trabalho tornaram-se questões que não poderão mais ser resolvidas, em pleno século XXI, nos planos estritamente nacionais. Por esta razão já se fala em Contratos Coletivos (no Brasil o termo legal é Convenção ou Acordo) transnacionais, incluindo todos os segmentos em que haja, efetivamente, trabalho - e os trabalhadores da Administração Pública, por óbvio, encontram-se aí contemplados. A tendência é oferecer uma contrarresposta à globalização hegemônica, que visa desregulamentar o trabalho e o remunerar cada vez de forma menos digna. Esse contraponto à globalização hegemônica serve para garantir em nível mundial, respeitando-se as peculiaridades culturais de cada país, um processo que pode ser denominado como de emancipação social. Por óbvio, a negociação coletiva de trabalho é um dos mais eficazes instrumentos para dação de direitos sociais aos trabalhadores e, consequentemente, promover sua emancipação social e individual ${ }^{15}$.

O Estado, portanto, em tempos hodiernos não pode afirmar a supremacia de seu interesse contra tudo e todos, pois ele não é mais apenas produtor de normas jurídicas, mas também sujeito dessas mesmas normas. Por decorrência lógica, não se pode alegar que o Estado estabelece unilateralmente as normas a serem seguidas; como se viu, na sociedade pós-moderna tal processo se dá de forma cada vez mais internacionalizada e com pluralidade de agentes.

Por esta produção eminentemente estatal dos diplomas jurídicos e do discurso voltado à proteção apenas do valor legal, que não questiona a legitimidade, é que a proteção aos direitos fundamentais resta fraca e não raro ineficiente, em especial quando o assunto versa sobre direitos dos trabalhadores, máxime quando

\footnotetext{
${ }_{14}$ ANDRADE, Everaldo Gaspar Lopes de. Direito do Trabalho e pós-modernidade: fundamentos para uma teoria geral. São Paulo: LTr, 2005, p. 208-211.

15 SANTOS, Boaventura de Sousa. Democratizar a democracia: os caminhos da democracia participativa. 4. ed. Rio de Janeiro: Civilização Brasileira, 2009, p. 22-25.
} 
sejam eles de cunho social. Esses discursos jurídicos não existem também por mera fatalidade, pois o poder - sobretudo o econômico - busca a produção de uma suposta verdade, e porque pela produção da suposta verdade é que se produz a riqueza; todos "estamos submetidos à verdade também no sentido em que ela é lei e produz o discurso verdadeiro que decide, transmite e reproduz, ao menos em parte, efeitos de poder" ${ }^{\prime \prime}$.

Portanto a lei, associada a mecanismos de poder, preenchem de verdade os discursos jurídicos que são interpretados até mesmo por quem vive a norma. Mas, afinal, a quem estes discursos jurídicos servem? Michel Foucault adverte: o poder não é apenas uma dominação exercida por um indivíduo sobre outros, ou um grupo sobre outros, ou uma classe sobre outras, mas sim algo que "funciona e se exerce em rede"17. A argumentação jurídica que negligencia os direitos fundamentais dos trabalhadores, assim como inúmeros outros mecanismos existentes em cadeia no corpo social, constituem toda a "micromecânica do poder que representou um interesse para a burguesia a partir de determinado momento"18.

Ora, convenções coletivas de trabalho celebradas com a Administração Pública são uma eficiente forma de controlá-la e talvez por isto, como se verá no texto, haja tanta resistência quanto à sua implementação no Brasil. Nesse aspecto eminentemente trabalhista, o Estado age como se seus servidores, a sociedade e a Administração vivessem em compartimentos estanques, e passa a exercer - muitas vezes de forma violenta - seus discursos jurídicos de poder. Nesse sentido basta verificar, como adiante se falará, a Ação Direta de Inconstitucionalidade 492, julgada em 12 de novembro de 1992, quando o STF declarou, por maioria, a inconstitucionalidade da alínea $d$ do art. 240 da Lei 8.112/90.

Outro argumento lançado contra a negociação coletiva na Administração ventilado na Ação citada, é o respeito ao princípio da legalidade. Não se poderia, pois, estabelecer-se questões trabalhistas - especialmente aquelas vinculadas ao salário - porque a remuneração deve estar prevista em Lei, cuja iniciativa deverá ser do chefe do Executivo. Todavia, isso não pode ser considerado empecilho para a negociação coletiva: a Lei de Diretrizes Orçamentárias é apresentada pela Presidência da República ao Congresso após vários acordos políticos firmados com outros entes; o mesmo se diga quanto às Constituições Estaduais (e servidores dos Estados-

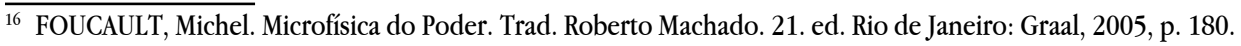
17 Idem, p. 183.

${ }^{18}$ Idem, p. 185.
} 
membros) e Leis Orgânicas de municípios (com relação aos servidores municipais). A Convenção Coletiva de trabalho poderia, sem dúvidas, refletir-se na Lei de Diretrizes Orçamentárias $^{19}$. Isto nada mais é do que a democratização da sociedade, no sentido exposto por Boaventura de Sousa Santos, em citação constante do presente item ${ }^{20}$.

Setores estratégicos ligados à própria sobrevivência do Estado, em regra, não têm direito sequer à sindicalização. É o que ocorre com os militares. Ainda assim, desde há muito, os pareceres da Organização Internacional do Trabalho recomendam que tais proibições poderão existir, mas, em contrapartida, o Estado deverá encontrar meios eficazes de negociação com tais setores ${ }^{21}$. Tais trabalhadores poderiam, por exemplo, valerem-se das câmaras setoriais de negociação, existentes desde o governo Collor que, apesar de concebidas em um contexto de liberalização da economia, pode dar respostas ágeis quanto a conflitos entre servidores e Administração. Sublinhe-se a tendência que cada vez mais se constata: a composição destas câmaras é tripartite, ou seja, o Estado - no mais das vezes em sua figura maior, a chefia do Executivo - foge ao monismo jurídico caracterizado pela unilateralidade das normas destinadas aos servidores públicos.

Desta forma, cabe analisar as transformações ocorridas no ordenamento jurídico brasileiro após a ratificação e promulgação da Convenção 151 e da Recomendação 159 da Organização Internacional do Trabalho e verificar a possibilidade ou não de negociação coletiva na Administração Pública brasileira, como ocorre em nações como Espanha, Itália ou mesmo em nosso vizinho Uruguai, como adiante se falará.

\section{AS CONVENÇÕES DA OIT ENQUANTO TRATADOS INTERNACIONAIS DE DI- REITOS HUMANOS}

As Convenções da Organização Internacional do Trabalho são tratados internacionais, na medida em que esse diploma "é o acordo formal, concluído entre sujeitos de direito internacional público, e destinado a produzir efeitos jurídicos" ${ }^{\text {"2 }}$.

\footnotetext{
${ }^{19}$ RESENDE, Renato de Sousa. Negociação coletiva de servidor público. São Paulo: LTr, 2012, p. 204-210.

${ }^{20}$ SANTOS, Boaventura de Sousa. Democratizar a democracia: os caminhos da democracia participativa. 4. ed. Rio de Janeiro: Civilização Brasileira, 2009, p. 22-25.

${ }^{21}$ VALTICOS, Nicolas. Derecho Internacional del Trabajo. Trad. José Maria Treviño. Madrid: Tecnos, 1977, p. 278.

${ }^{22}$ REZEK, José Francisco. Direito internacional público: curso elementar. 8. ed. São Paulo: Saraiva, 2000, p. 14.
} 
De maneira bastante simples, as Convenções da OIT são instrumentos abertos por prazo indeterminado aos Estados para ratificação, por meio dos quais os países firmam o compromisso de assegurar os direitos ali previstos.

Assim, o que é necessário esclarecer, para o aprofundamento da análise do tema deste artigo, é se tais Convenções podem ou não ser qualificadas como tratados internacionais de direitos humanos, pois somente os tratados que possuem tal natureza é que produzem direitos que podem vir a ser considerados como direitos fundamentais, de acordo com o art. $5^{\circ}, \S \S 2^{\circ}$ e $3^{\circ}$ da Constituição brasileira de 1988.

Mas, antes de se passar a fazer tal investigação, é necessário que se faça alguns esclarecimentos preliminares acerca da categoria "direitos humanos", tendo em vista a pluralidade de significados atribuídos a esta denominação, seja no âmbito da academia ou das entidades que militam na área.

Jorge Miranda $^{23}$ esclarece que na expressão direitos fundamentais revelam-se os mesmos direitos humanos, mas positivados na ordem jurídica, mormente no plano da Constituição. No plano internacional, porém, prevalece o termo direitos humanos, demonstrando ficar mais clara a preocupação com o ser humano individualmente considerado, constituindo uma espécie de "mínimo ético" a ser seguido pelos Estados. De fato, a afirmação encontra respaldo não apenas na Declaração Universal dos Direitos do Homem, de 1948, como também na francesa Declaração de Direitos do Homem e do Cidadão, de 1789, embora ambas possuam propósitos bastante distintos em termos históricos.

$\mathrm{O}$ homem não pode realmente protagonizar uma existência livre, plenamente humana, caso encontre-se diante do não atendimento de necessidades básicas para sua existência. Para existir e ser livre de fato o homem precisa ver concretizadas estas necessidades. E se há meios materiais e técnicos para que tais necessidades básicas sejam concretizadas, elas devem sê-lo. Francisco J. Contreras Peláez, que estabelece estas reflexões, considera-as em princípio bastante ingênuas ${ }^{24}$. Provavelmente porque, como quer Paulo Bonavides, esses direitos de segunda dimensão (ou direitos sociais) tiveram historicamente uma normatividade baixa, ou de eficácia duvidosa ${ }^{25}$.

De qualquer sorte os direitos sociais, ou direitos à igualdade, existem justamente por reconhecer, no homem, a sua desigualdade material. Mas, para a

${ }_{23}$ MIRANDA, Jorge. Manual de Direito Constitucional. 3. ed. Coimbra: Coimbra, 2000. v. 4, p. 51-55.

${ }^{24}$ CONTRERAS PELÁEZ, Francisco J. Derechos sociales: teoría e ideología. Madrid: Tecnos, 1994, p. 41.

25 BONAVIDES, Paulo. Curso de Direito Constitucional. 19. ed. São Paulo: Malheiros, 2006, p. 564. 
realização plena da igualdade entre os homens, é preciso verificar, segundo Norberto Bobbio: a) quais os sujeitos entre os quais se devem repartir os bens e os ônus; $b$ ) quais bens e quais ônus devem ser repartidos entre os indivíduos; c) qual o critério a ser adotado para a repartição $0^{26}$.

A principal característica dos direitos de segunda dimensão diz respeito ao fato de que, em regra, a sua realização depende de uma prestação por parte do Estado, em vez da abstenção do ente (como ocorre com os de primeira dimensão), razão pela qual se diz que são direitos de caráter positivo. Porém, como ressaltam Gilmar Ferreira Mendes e Paulo Branco, os direitos de segunda dimensão também abrangem os direitos trabalhistas oriundos das conquistas das lutas dos trabalhadores por melhores condições de trabalho e os meios necessários para o exercício de suas reivindicações ${ }^{27}$.

O mundo, em verdade, passa por um processo que pode ser denominado como garantismo, ou paradigma garantista: direitos fundamentais, específicos ou não, devem ser garantidos pelo Estado em diversas formas. O ente público, nessa visão, não apenas se impõe limitações para tolher direitos individuais, mas também cria vínculos com a sociedade. Não deve apenas proibir as lesões, como também se obriga a prestações, a fim de equilibrar as relações entre capital e trabalho. Isso pode significar o início de um caminho rumo à verdadeira autonomia contratual dos trabalhadores, para que se rompesse em definitivo o liame entre trabalbo e sobrevivência: com maior poder e mais direitos conferidos, os trabalhadores poderiam aos poucos libertar-se de trabalhos que apenas thes conferem subsistência, com pouca ou nenhuma dignidade ${ }^{28}$. E se o Estado segue tal paradigma, que é o ponto fulcral e definidor dos direitos humanos, também haverá de submeter-se às leis que impõe aos particulares, sobretudo por meio do exemplo: tratar seus próprios servidores com iguais direitos àqueles impostos para o setor privado (e, quem sabe, também igualar os empregados da iniciativa privada quanto a certas garantias existentes apenas no âmbito do funcionalismo público).

\footnotetext{
${ }^{26}$ BOBBIO, Norberto. Direita e esquerda: razões e significados de uma distinção política. Trad. Marco Aurélio Nogueira. São Paulo: UNESP, 1995, p. 96.

${ }^{27}$ MENDES, Gilmar Ferreira; BRANCO, Paulo Gustavo Gonet. Curso de Direito Constitucional. 9. ed. São Paulo: Saraiva, 2014, p. 145. Embora os autores se refiram a direitos fundamentais, é evidente que a caracterização de tais direitos também se aplica aos direitos humanos, tendo em vista que, como dito acima, a classificação dos direitos em gerações vem sendo utilizada tanto para classificar os direitos fundamentais quanto os direitos humanos, sendo que a diferença entre essas duas categorias de direitos não diz respeito ao conteúdo ou à natureza dos direitos, mas sim ao instrumento normativo em que estão previstos.

${ }^{28}$ FERRAJOLI, Luigi, op. cit., p. 85-86.
} 
É nesse ponto que se pode observar que os direitos trabalhistas, dentre os quais se insere o direito à negociação coletiva, possuem natureza de direitos humanos, razão pela qual as Convenções da OIT, que asseguram direitos aos trabalhadores, podem ser consideradas como tratados internacionais de direitos humanos. Também corrobora essa afirmação o fato de a Declaração Universal de Direitos Humanos da ONU prever, em seu artigo $23^{\circ}$, a proteção aos direitos dos trabalhadores e até mesmo o direito à sindicalização como direitos de cidadania ${ }^{29}$.

$\mathrm{O}$ artigo $5^{\circ}, \S 2^{\circ}$ da Constituição Federal instituiu no Brasil um sistema aberto de direitos fundamentais, o que significa dizer que o catálogo de direitos previsto no Título II da Lei Maior não pode ser considerado taxativo. Há até mesmo a previsão de direitos fundamentais inespecíficos, ou seja, aqueles que, previsto a indivíduos ou grupos, se exercidos no local do trabalho ou para ele, tornam-se direitos fundamentais de cunho social. Direitos de personalidade, como o de imagem, podem ganhar inegável conteúdo de direito social ${ }^{30}$. Entretanto, a aplicabilidade do dispositivo, no que diz respeito aos tratados internacionais de direitos humanos, tem sido objeto de muitas controvérsias no âmbito da doutrina e da jurisprudência. $\mathrm{Na}$ tentativa de elucidar tal questão, o poder constituinte derivado, quando da edição da EC 45/2004, inseriu na Carta Magna o $\$ 3^{\circ}$ no artigo $5^{\circ}$, o qual prevê que os tratados internacionais de direitos humanos que forem aprovados em cada Casa do Congresso Nacional, em dois turnos, por três quintos dos votos dos respectivos membros, serão equivalentes às emendas constitucionais.

O entendimento atual do Supremo Tribunal Federal a respeito do assunto é no sentido de que os direitos previstos em tais tratados teriam hierarquia superior à da legislação infraconstitucional, mas seriam inferiores à Constituição, possuindo, assim, o status sui generis de norma supralegal ${ }^{31}$. Entretanto, há também corrente

${ }^{29}$ Quanto aos direitos de terceira dimensão, que são considerados aqueles que possuem natureza transindividual, englobando os direitos de titularidade difusa ou coletiva, e às teorias doutrinárias que consideram existir outras dimensões além dessas três propostas, não serão apresentados maiores comentários pelo fato de tal aprofundamento ser prescindível para a análise do tema deste trabalho.

${ }^{30}$ GUTIÉRREZ PÉREZ, Miguel. Ciudadanía en la empresa y derechos fundamentales inespecíficos. Murcia: Laborum, 2011, p. 17-19.

${ }^{31}$ No HC 88.240, Rel. Min. Ellen Gracie, DJ de 24/10/2008, assentou-se: 'A esses diplomas internacionais sobre direitos humanos é reservado o lugar específico no ordenamento jurídico, estando abaixo da Constituição, porém acima da legislação interna. O status normativo supralegal dos tratados internacionais de direitos humanos subscritos pelo Brasil torna inaplicável a legislação infraconstitucional com ele conflitante, seja ela anterior ou posterior ao ato de ratificação'. No mesmo sentido, o HC 94.702, da mesma relatora e publicado na mesma data. Esses precedentes citam e seguem o HC 90.171, Rel. Min. Gilmar Mendes, DJ de 17/08/2007. Nesse sentido, MENDES, Gilmar Ferreira; BRANCO, Paulo Gustavo Gonet, op. cit., p. 139-140. 
doutrinária bastante significativa ${ }^{32}$ a considerar que a previsão do artigo $5^{\circ}, \S^{\circ}$ da Constituição da República não implicaria no reconhecimento de que apenas e tão-só os tratados aprovados de acordo com o procedimento formal estabelecido pela Emenda Constitucional 45/2004 poderiam ter status de norma constitucional. Para essa corrente, o artigo $5^{\circ}, \S 3^{\circ}$ não configuraria um requisito para a atribuição de estatura constitucional aos tratados de direitos humanos, mas apenas tornaria os direitos previstos nos tratados, além de materialmente, também formalmente constitucionais.

De fato, não há como negar que seriam absolutamente inúteis as disposições do artigo $5^{\circ}, \S 2^{\circ}$ da Carta Magna no sentido de considerar os direitos humanos presentes em tratados internacionais como parte integrante do rol de direitos fundamentais protegidos pela Constituição, caso se considerasse que apenas com o advento do artigo $5^{\circ}$, $\S^{\circ}$ é que os direitos previstos nos tratados de direitos humanos poderiam passar a equivaler aos direitos fundamentais já presentes no excelso texto. No mais, a Constituição poderá possuir diversos intérpretes, como afirma Peter Häberle ${ }^{33}$; com efeito, não está ela apenas vinculada ao que o Estado e os seus órgãos jurisdicionais afirmam, mas também às partes dos processos, aos juristas, aos legisladores e aos grupos sociais organizados, máxime em sindicatos. A interpretação constitucional é, pois, um conceito sempre aberto, admitindo-se novas alternativas de solução a um caso concreto, e não apenas um processo passivo de submissão a uma ordem.

Destarte, ao se ampliar o leque de possíveis intérpretes da Constituição busca-se a integração da realidade nesse processo interpretativo ${ }^{34}$, o que implica afirmar que o direito à negociação coletiva na Administração Pública é revestido da marca de fundamentalidade. Embora seja direito fundamental inespecífico, existe e ganha legitimidade pela interpretação de todos - de legisladores a julgadores - incluindo, por óbvio, a própria sociedade que vive o direito e também os trabalhadores da Administração, além dos próprios gestores administrativos. Todas essas interpretações contribuem para o primado do trabalho e de sua valorização, nos exatos termos do artigo $1^{\circ}$ do excelso texto.

\footnotetext{
${ }^{32}$ A título exemplificativo pode-se citar PIOVESAN, Flávia. Direitos humanos e o Direito Constitucional internacional. 14. ed. São Paulo: Saraiva, 2013; e MAZZUOLI, Valério de Oliveira. O novo $§ 3^{\circ}$ do art. $5^{\circ}$ da Constituição e sua eficácia. Revista Forense, Rio de Janeiro, v. 378, n. 101, p. 89-109, mar./abr. 2005.

33 HÄBERLE, Peter. Hermenêutica constitucional: a sociedade aberta dos intérpretes da Constituição - contribuição para a interpretação pluralista e "procedimental" da Constituição. Trad. Gilmar Ferreira Mendes. Porto Alegre: Sérgio Antônio Fabris, 1997, p. 30.

${ }^{34}$ HESSE, Konrad. A força normativa da Constituição. Trad. Gilmar Ferreira Mendes. Porto Alegre: Sérgio Antônio Fabris, 1991, p. 13-19.
} 


\section{A CONVENÇÃO 151 DA OIT E O DIREITO FUNDAMENTAL DOS TRABALHA- DORES DA ADMINISTRAÇÃO PÚBLICA À NEGOCIAÇÃO COLETIVA}

Apesar de o ambiente laboral das instituições públicas também ser marcado por uma conflitualidade entre trabalhadores e a Administração, para além de tais trabalhadores igualmente possuírem reivindicações pautadas por seus sindicatos de classe, a legislação brasileira não assegura taxativamente o direito à negociação coletiva a tal classe, embora a Constituição Federal tenha feito sensíveis avanços no sentido de equiparar os trabalhadores da Administração aos da iniciativa privada ${ }^{35}$.

Tal resistência advém do fato de que, no Brasil, a concessão de aumentos e reajustes aos trabalhadores da Administração depende de lei de iniciativa do chefe do Poder Executivo e de previsão orçamentária. No julgamento da Ação Direta de Inconstitucionalidade 492, em 12 de novembro de 1992, o STF declarou, por maioria, a inconstitucionalidade da alínea $d$ do art. 240 da Lei 8.112, de 11 de dezembro de 1990, que estabelecia aos servidores públicos o direito à negociação coletiva ${ }^{36}$. Após vários julgados que reproduziram o entendimento acima narrado, o Supremo Tribunal Federal o consolidou editando a Súmula 679, com sucinto enunciado: "a fixação de vencimentos dos servidores públicos não pode ser objeto de convenção coletiva" ${ }^{37}$.

A Súmula, à época de sua edição e mesmo antes dela, representa um retrocesso na experiência brasileira. Em muitos municípios brasileiros reivindicações e greves de servidores públicos acabaram por lograr sucesso para o estabelecimento de diversas questões do funcionalismo público, inclusive salário. Mesmo em âmbito nacional foi criada, em 2003, a Mesa Nacional de Negociação Permanente, a fim de instituir sistema de negociação permanente em âmbito federal ${ }^{38}$. Mais à frente, objetivando a resolução de conflitos entre servidores do Executivo e a União, criou-se o Subsistema de Relações de Trabalho no Serviço Público Federal, a fim de estabelecer diálogo constante entre os servidores públicos, o Ministério do

\footnotetext{
35 A título de exemplo, pode-se citar o direito à sindicalização e à greve, que foi previsto aos servidores e empregados públicos pela Constituição de 1988 de maneira inédita, e o disposto no art. 39 , $\$ 3^{\circ}$, que estendeu vários direitos trabalhistas previstos no art. $7^{\circ} \mathrm{da}$ Carta Magna aos trabalhadores da Administração Pública.

36 SUPREMO Tribunal Federal. Ação Direta de Inconstitucionalidade 492. Disponível em: < http://www.stf.jus. $\mathrm{br} /$ portal $/$ processo $/$ verProcessoAndamento.asp?numero $=492 \&$ classe $=$ ADI $\&$ codigoClasse $=0 \&$ origem $=\mathrm{JU}$ $\mathrm{R} \&$ recurso $=0 \&$ tipoJulgamento $=\mathrm{M}>$. Acesso em: 25 jan. 2016.

37 SUPREMO Tribunal Federal. Súmulas $\mathrm{n}^{\circ}$ 601-700. Disponível em: <http://www.stf.jus.br/portal/ $\mathrm{cms} /$ verTexto.asp?servico $=$ jurisprudenciaSumula\&pagina $=$ sumula_601_700 > . Acesso em: 25 jan. 2016.

38 SANTOS, Enoque Ribeiro dos. Negociação coletiva de trabalho nos setores público e privado. São Paulo: LTr, 2015, p. 177.
} 
Planejamento, Orçamento e Gestão e os Ministérios nos quais os servidores estejam lotados. Trata-se de mais uma forma estabelecida pela Administração Federal, por meio do Decreto 7.674/2012, para solucionar termos e condições de trabalho e, assim, evitar conflitos trabalhistas na esfera administrativa ${ }^{39}$.

Também é útil salientar que a jurisprudência do Tribunal Superior do Trabalho negava aos servidores públicos o direito à negociação coletiva, consoante redação original da Orientação Jurisprudencial 5 da Seção de Dissídios Coletivos do TST, criada em 27 de março de 1998: "aos servidores públicos não foi assegurado o direito ao reconhecimento de acordos e convenções coletivos de trabalho" ${ }^{\prime 4}$. A vedação não se aplicava, porém, aos chamados empregados públicos, ou às pessoas que fossem subordinadas a pessoas jurídicas de direito privado que, embora com capital público, procedessem à exploração de atividade econômica. Nesse caso, segue-se o artigo $173, \S 1^{\circ}$ da Constituição Federal ${ }^{41}$.

Tal situação, entretanto, começou a se modificar em 2010, quando o Brasil ratificou a Convenção 151 e a Recomendação 159 da Organização Internacional do Trabalho, as quais versam sobre as relações de trabalho na Administração Pública e preveem o direito dos servidores públicos à negociação coletiva. Esses diplomas internacionais foram aprovados pelo Parlamento por meio do Decreto Legislativo 206/2010 ${ }^{42}$ o qual, por sua vez, fundamentou o Decreto 7.944/2013 ${ }^{43}$, que promulgou a Convenção e a Recomendação acima mencionadas, completando o procedimento necessário para que elas produzissem efeitos no Brasil. Uma primeira repercussão importante que é digna de nota diz respeito à alteração do entendimento jurisprudencial do Tribunal Superior do Trabalho quanto à possibilidade de realização de negociação coletiva no âmbito dos entes estatais que tivessem empregados contratados pelo regime de direito privado.

Com efeito, após a ratificação da convenção supramencionada, a Orientação Jurisprudencial 5 da Seção de Dissídios Coletivos (SDC) sofreu substancial alteração:

\footnotetext{
$\overline{39}$ BRASIL. Decreto 7.674, de 20 de janeiro de 2012. Diário Oficial da União, Brasília, v. 149, n. 16, 23 jan. 2012. Seção 1, p. 1.

${ }^{40}$ Embora a OJ em questão faça menção a "servidores públicos", é possível concluir que a orientação jurisprudencial dizia respeito aos empregados públicos, haja vista que somente estes estão submetidos à jurisdição da Justiça do Trabalho.

${ }^{41}$ RESENDE, Renato de Sousa, Op. cit., p. 177.

${ }^{42}$ BRASIL. Decreto Legislativo 206, de 07 de abril de 2010. Diário Oficial da União, Brasília, v. 147, n. 66, 08 abr. 2010. Seção 1, p. 4.

${ }^{43}$ BRASIL. Decreto 7.944, de 06 de março de 2013. Diário Oficial da União, Brasília, v. 150, n. 45, 07 mar. 2013. Seção 1, p. 1.
} 
DISSÍDIO COLETIVO. PESSOA JURÍDICA DE DIREITO PÚBLICO. POSSIBILIDADE JURÍDICA. CLÁUSULA DE NATUREZA SOCIAL. Em face de pessoa jurídica de direito público que mantenha empregados, cabe dissídio coletivo exclusivamente para apreciação de cláusulas de natureza social. Inteligência da Convenção $n^{0} 151$ da Organização Internacional do Trabalho, ratificada pelo Decreto Legislativo $\mathrm{n}^{\mathrm{O}} 206 / 2010^{44}$.

Assim, embora tenha permanecido a restrição em relação à negociação coletiva que tenha por objetivo os aumentos e reajustes dos servidores públicos, em razão da necessidade de previsão orçamentária delineada em Projeto de Lei de iniciativa do chefe do Executivo, respeitando-se os limites da Lei de Responsabilidade Fiscal (Lei Complementar 101/2000), não se pode negar que a alteração da redação do $\mathrm{OJ} 5 \mathrm{da}$ SDC representa um importante avanço no que diz respeito à possibilidade dos servidores públicos apresentarem reivindicações por meio de suas entidades de representação de classe, caso se adote interpretação extensiva do verbete sumular. As Convenções e os Acordos poderão versar sobre os mais diversos temas, como compensação de horários no trabalho, proibição de quaisquer atos discriminatórios, etc.

Além disso, considerando que tanto os empregados públicos quanto os servidores públicos submetidos ao regime estatutário são contemplados pelas disposições do artigo $1^{\mathrm{O}}$, inciso I da Convenção $151 \mathrm{da}$ OIT, constantes do Decreto 7.944/2013, e que as Convenções da OIT devem ser consideradas como tratados internacionais de direitos humanos em razão do disposto no artigo $5^{\circ}, \S 2^{\circ} \mathrm{da}$ Constituição Federal, não há dúvida de que, com a ratificação da Convenção e da Recomendação já citadas, surgiu para os trabalhadores da Administração o direito fundamental à negociação coletiva. Feita esta afirmação, cumpre analisar algumas das principais consequências do reconhecimento desse direito fundamental.

Sabe-se que a caracterização de determinados direitos como fundamentais traz uma série de implicações jurídicas ao ordenamento, na medida em que repercutem sobre a atividade legislativa do Estado, seja incitando o Poder Legislativo a regulamentar tais direitos, seja coibindo a elaboração de normas contrárias a esses direitos fundamentais. Todavia, poderá haver uma consequência particularmente importante para a viabilização do exercício do direito fundamental à negociação coletiva dos servidores e empregados públicos, que corresponde à possibilidade de

${ }_{44}$ BRASIL. Tribunal Superior do Trabalho. Diário Eletrônico da Justiça do Trabalho, Brasília, n. 1071, 25 set. 2012. p. 103. 
tal direito ser regulamentado pelo Poder Judiciário, ainda que provisoriamente, por meio de Mandado de Injunção, eis tratar-se de um direito integrado à Constituição Federal. A casuística apresentada não é nova: o direito de greve no serviço público, por exemplo, até hoje não foi regulamentado senão pela via do Mandado de Injunção, que aplica ao caso os mesmos procedimentos previstos na Lei 7.783/89, a qual foi concebida para regulamentar o direito de greve no setor privado.

Com efeito, sendo evidentemente necessária a existência de uma regulamentação legal no âmbito do ordenamento jurídico brasileiro para que o direito fundamental à negociação coletiva possa ser exercido (e o direito à negociação coletiva é corolário e decorrência lógica do direito à sindicalização), conclui-se que a omissão do legislador em regulamentar tal direito ensejará a interposição de Mandado de Injunção, nos termos do artigo $5^{\circ}$, inciso LXXI da Constituição Federal.

Desde o julgamento dos Mandados de Injunção 670, 708 e 712, os quais versaram sobre o direito de greve dos servidores públicos, o entendimento do Supremo Tribunal Federal se consolidou no sentido de que, ao proferir uma decisão em sede de Mandado de Injunção, o Judiciário, além de declarar a existência da omissão legislativa, poderá criar regulamentação provisória do direito cujo exercício esteja prejudicado por essa omissão, de modo a viabilizar a efetividade de uma garantia constitucional ${ }^{45}$. Logo, ainda que o Poder Legislativo relute em proceder à regulamentação do direito dos empregados e servidores públicos à negociação coletiva, as entidades sindicais poderão pleitear regulamentação provisória junto ao Judiciário de modo a possibilitar o exercício desse direito.

Entende-se que, inobstante as objeções apresentadas pelo STF e pelo TST à existência de negociações coletivas que versem sobre a remuneração de empregados e servidores públicos - ante a exigência de previsão legal que assegure os reajustes e/ou aumentos concedidos a tais trabalhadores - é possível estabelecer uma regulamentação que permita que a negociação não se restrinja apenas às cláusulas de natureza social, abrangendo pelo menos uma parte do procedimento necessário para a alteração da remuneração dos trabalhadores.

Experiência jurídica interessante para a solução de impasses de natureza econômica entre servidores e empregados públicos e a Administração é aquela existente no Uruguai. Há negociações informais quanto a reajustes salariais do funcionalismo, que são pactuadas entre o sindicato da categoria e os Poderes

${ }^{45}$ MENDES, Gilmar Ferreira; BRANCO, Paulo Gustavo Gonet. Curso de Direito Constitucional. 9. ed. São Paulo: Saraiva, 2014, p. 1117. 
Executivo e Legislativo. Por força da Convenção 151 da OIT, estes acordos oriundos de negociação coletiva, embora informais, ganham peso e obrigam os entes estatais a concederem, em forma de Lei, o que foi pactuado ${ }^{46}$. A negociação coletiva tem, portanto, função jurídica e também política, o que deve ser melhor explorado pela doutrina e jurisprudência brasileiras.

O Estado moderno é apenas uma das partes integrantes do sistema sociopolítico existente na sociedade, sistema este que é submisso ao ordenamento jurídico que ele mesmo cria ${ }^{47}$; a Administração torna-se, pois, sujeito de direito e de deveres na órbita jurídica, e entre estes deverá compreender-se a negociação coletiva não apenas de natureza social, mas também econômica, ainda que seja feita por pactos políticos. Todas essas disposições informalmente ajustadas ganham respaldo jurídico por meio da norma supralegal existente no Decreto 7.944/2013, e à vinculação que o Estado cria com os diversos setores em termos de garantia de direitos sociais, como explícito na citada lição de Luigi Ferrajoli.

Apesar de ainda não existir o instituto da negociação coletiva de natureza econômica aplicável aos trabalhadores da Administração Pública no ordenamento jurídico brasileiro, desde o ano de 2003 existe a Mesa Nacional de Negociação Permanente do serviço público federal, composta pelas bancadas do governo e dos sindicatos. Seu objetivo é viabilizar o diálogo da Administração Pública, sobretudo por meio do Ministério do Planejamento, Orçamento e Gestão, com as entidades sindicais que representam os servidores públicos. Tem sido bastante comum a existência de negociações entre a Administração Pública Federal e as entidades sindicais no tocante até mesmo a questões de natureza econômica, que têm resultado na elaboração de Medidas Provisórias, posteriormente convertidas em Lei, ou em Projetos de Lei que concedem aumentos e reajustes a tais servidores, estabelecendo até mesmo planos de cargos vantajosos para eles ${ }^{48}$.

A título de exemplo, citem-se casos analisados por Silvestrin, cuja pesquisa mostra que alguns termos de acordos firmados entre a Administração e entidades sindicais representativas dos servidores públicos do Ministério do Trabalho e

${ }^{46}$ RODRIGUEZ, José Rodrigo. Dogmática da liberdade sindical: direito, política, globalização. Rio de Janeiro: Renovar, 2003, p. 298-299.

47 BOBBIO, Norberto. Estado, governo, sociedade: para uma teoria geral da política. Trad. Marco Aurélio Nogueira. São Paulo: Paz e Terra, 2012, p. 197.

${ }^{48}$ SILVESTRIN, Edilene Freccia. Estudo comparativo das negociações coletivas realizadas junto às categorias dos servidores do Ministério do Trabalho e Emprego (MTE) e do Instituto Nacional do Seguro Social (INSS). Monografia (Especialização em Negociação Coletiva) - Universidade Federal do Rio Grande do Sul, Porto Alegre, 2010 , p. 68. 
Emprego e do Instituto Nacional de Seguro Social, em 2008, efetivamente resultaram em majoração da remuneração de tais servidores conquistada, inicialmente, por meio de Medida Provisória e, posteriormente, por Leis que refletiam os acordos já firmados ${ }^{49}$. Tratava-se, pois, de medida já concertada entre os atores sociais envolvidos, atores estes que, curiosamente, encontravam-se todos ligados ao Estado.

Assim, se já há exemplos de Leis que estabelecem aumentos e reajustes e que criam planos de carreira para servidores públicos a partir de negociações ocorridas entre a Administração Pública Federal e entidades sindicais, mesmo sem que haja regulamentação legal de tais negociações, já se pode concluir que é possível admitir essa forma de negociação como parte do procedimento necessário para o regramento - até mesmo, frise-se - de questões de natureza econômica aos trabalhadores da Administração Pública.

Isto tem acontecido porque, mesmo que não seja possível obrigar o Poder Legislativo a legislar em favor dos servidores e empregados públicos, o Poder Executivo pode se comprometer a criar medidas provisórias ou, pelo menos, propor Projeto de Lei prevendo os aumentos ou reajustes para os seus servidores que resultarem do processo negocial, já que se trata de matéria legislativa cuja iniciativa é exclusiva do chefe do Poder Executivo (artigo 61, $\$ 1^{\circ}$, II, alínea c da Constituição Federal). É possível conceber, portanto, uma regulamentação de negociação coletiva que, vinculando ou não a atuação legislativa do parlamento, estabeleça a obrigação do chefe de cada Poder de propor Projeto de Lei respectivo ou, no caso específico do Executivo, a criar uma medida provisória para tornar concreto o que foi objeto de consenso na negociação coletiva.

\section{CONCLUSÃO}

Ao longo do presente artigo, observou-se ser possível afirmar que, com a ratificação da Convenção 151 e da Recomendação 159 da OIT pelo Brasil, por meio do Decreto Legislativo 206/2010, o qual fundamenta o Decreto 7.944/2013, os trabalhadores da Administração Pública passaram a ter o direito fundamental à negociação coletiva, tendo em vista que tal afirmação encontra amparo nas normas inscritas no ordenamento jurídico brasileiro. A Constituição, embora silente acerca

$\overline{49}$ SILVESTRIN, Edilene Freccia, op. cit., p. 92-115. 
do tema, permitiu que se revogasse qualquer disposição contrária à negociação coletiva quanto ao servidor público, vez que o aludido diploma internacional possui o caráter sui generis de norma supralegal.

Em verdade, o instrumento normativo internacional preenche lacuna ontológica no ordenamento jurídico brasileiro, pois direitos coletivos de natureza trabalhista, ainda que em uma relação de trabalho de cunho administrativo, sempre são representadas por um triângulo equilátero: direito à sindicalização, à negociação coletiva e à greve. A razão é simples: por meio de sindicatos os interesses coletivos dos trabalhadores são defendidos; para a defesa de tais direitos, o sindicato tem o dever-poder de entabular negociação com o ente público e, restando frustrada a possibilidade de acordo, é reconhecido o direito fundamental à greve, instrumento legítimo para autotutela de interesses dos trabalhadores.

A Constituição Federal de 1988 surgiu com uma falha dogmática: reconheceu os direitos fundamentais de sindicalização e de greve aos servidores públicos sem, contudo, estabelecer a possibilidade de negociação coletiva de trabalho. Isso permite, grosso modo, que os sindicatos de servidores públicos restem esvaziados em uma de suas principais funções e poderes, qual seja, a de negociar. Além disso, o direito de greve no serviço público até hoje não foi regulamentado senão pela via do Mandado de Injunção, que aplica ao caso os mesmos procedimentos previstos na Lei 7.783/89, que cuida da greve no setor privado. Havia, portanto, um marco nebuloso para o funcionamento do sistema sindical: caso os servidores se sentissem insatisfeitos, a rigor, deveriam desde logo proceder à greve, pois poder de negociar inexistia.

Viu-se, porém, que a negociação coletiva na Administração Pública obteve experiências exitosas no Brasil, desde negociações em sindicatos do funcionalismo municipal até a citada Mesa Nacional de Negociação Permanente, vinculada ao Ministério do Planejamento, Orçamento e Gestão. As possibilidades de negociação coletiva na Administração paulatinamente ampliaram-se, como se observa, por exemplo, no Decreto 7.674/2012. Os diplomas internacionais citados foram recebidos no plano nacional como normas supralegais, o que, só por si, já baliza um mínimo de regulamentação legal para o exercício do direito à negociação coletiva que, por ser corolário decorrente dos direitos fundamentais à sindicalização e à greve, é também direito fundamental.

A experiência jurídica uruguaia, desde já, é caminho de todo válido para que se admita a negociação com entidades sindicais de servidores públicos no afã 
de tratar de questões remuneratórias. O Brasil também poderá assim proceder, pois a função da negociação coletiva ultrapassa os limites do jurídico para adentrar o político: trata-se, acima de tudo, de um processo de concertação social, tendo como princípios norteadores a paz social e a colaboração.

No mais, até a incipiente experiência brasileira demonstra que já é possível superar alguns posicionamentos consolidados na jurisprudência do Tribunal Superior do Trabalho e do Supremo Tribunal Federal, no sentido de não admitir, em hipótese alguma, negociações coletivas que tenham por objeto a remuneração de servidores ou empregados públicos. Ora, nada impede que o sindicato passe a contar, em sua negociação, além de representantes do Executivo, também de outros do Legislativo. O acordo, embora político, poderá ter força para depois vincular os agentes públicos, superando os óbices que os Tribunais brasileiros sempre colocam à questão.

No plano ideal, seria preciso legislação apta a regulamentar o exercício desse direito pelos servidores da Administração Pública de forma bastante ampla, como observado nas experiências italianas e espanholas ou, ainda, Mandado de Injunção para que o Judiciário traçasse regras mínimas para a negociação coletiva compulsória no âmbito da Administração. A superação de óbices dessa natureza é de suma importância para que a futura regulamentação do direito supramencionado não o deixe tão aquém do poder negocial que é concedido às entidades sindicais dos trabalhadores da iniciativa privada, de maneira a vincular a atuação da Administração ao cumprimento de acordos politicamente pactuados com o funcionalismo. Não há obstáculos, pois, para que esta atuação também possa vincular o Poder Legislativo, caso haja representantes parlamentares especificamente designados para participar do processo negocial.

\section{REFERÊNCIAS}

ALONSO OLEA, Manuel. Derecho del Trabajo. Atualiz. Maria Emilia Casas Baamonde. 26. ed. Madrid: Civitas, 2009.

ANDRADE, Everaldo Gaspar Lopes de. Direito do Trabalho e pós-modernidade: fundamentos para uma teoria geral. São Paulo: LTr, 2005. 
BOBBIO, Norberto. Direita e esquerda: razões e significados de uma distinção política. Trad. Marco Aurélio Nogueira. São Paulo: UNESP, 1995.

BOBBIO, Norberto. Estado, governo, sociedade: para uma teoria geral da política. Trad. Marco Aurélio Nogueira. São Paulo: Paz e Terra, 2012.

BONAVIDES, Paulo. Curso de Direito Constitucional. 19. ed. São Paulo: Malheiros, 2006.

BRASIL. Decreto 1.256, de 29 de setembro de 1994. Diário Oficial da União, Brasília, v. 132, n. 188, 30 set. 1994. Seção 1, p. 14823.

BRASIL. Decreto 7.674, de 20 de janeiro de 2012. Diário Oficial da União, Brasília, v. 149, n. 16, 23 jan. 2012. Seção 1, p. 1.

BRASIL. Decreto 7.944, de 06 de março de 2013. Diário Oficial da União, Brasília, v. 150 , n. 45, 07 mar. 2013. Seção 1, p. 1.

BRASIL. Decreto Legislativo 206, de 07 de abril de 2010. Diário Oficial da União, Brasília, v. 147, n. 66, 08 abr. 2010. Seção 1, p. 4.

BRASIL. Lei 7.783, de 28 de junho de 1989. Diário Oficial da União, Brasília, v. 128, n. 122, 29 jun. 1990. Seção 1, p. 10561-10562.

BRASIL. Lei 8.112, de 11 de dezembro de 1990. Diário Oficial da União, Brasília, v. 128 , n. 237, 12 dez. 1990. Seção 1, p. 23935-23946.

BRASIL. Lei Complementar 101, de 04 de maio de 2000. Diário Oficial da União, Brasília, v. 138, n. 86, 05 mai. 2000. Seção 1, p. 1-9.

CARINCI, Franco; TAMAJO, Raffaele de Luca; TOSI, Paolo; TREU, Tiziano. Derecho del Trabajo: el derecho sindical. Trad. José Antonio Fernández Avilés. v. 1. 6. ed. Granada: Comares, 2015.

CONTRERAS PELÁEZ, Francisco J. Derechos sociales: teoría e ideología. Madrid: Tecnos, 1994.

GHERA, Edoardo. Diritto del Lavoro. 17 ed. Bari: Cacucci, 2012. 
GUTIÉRREZ PÉREZ, Miguel. Ciudadanía en la empresa y derechos fundamentales inespecíficos. Murcia: Laborum, 2011.

HÄBERLE, Peter. Hermenêutica constitucional: a sociedade aberta dos intérpretes da Constituição - contribuição para a interpretação pluralista e "procedimental" da Constituição. Trad. Gilmar Ferreira Mendes. Porto Alegre: Sérgio Antônio Fabris, 1997.

HESSE, Konrad. A força normativa da Constituição. Trad. Gilmar Ferreira Mendes. Porto Alegre: Sérgio Antônio Fabris, 1991.

MAZZUOLI, Valério de Oliveira. O novo $\S 3^{\circ}$ do art. $5^{\circ}$ da Constituição e sua eficácia. Revista Forense, Rio de Janeiro, v. 378, n. 101, p. 89-109, mar./abr. 2005.

MENDES, Gilmar Ferreira; BRANCO, Paulo Gustavo Gonet. Curso de Direito Constitucional. 9. ed. São Paulo: Saraiva, 2014.

MIRANDA, Jorge. Manual de Direito Constitucional. 3. ed. Coimbra: Coimbra, 2000. v. 4 .

NASCIMENTO, Amauri Mascaro. Ordenamento jurídico trabalhista. São Paulo: LTr, 2013.

PAES, Arnaldo Boson. Negociação coletiva na função pública: abordagem crítica do modelo brasileiro a partir do paradigma espanhol. São Paulo: LTr, 2013.

PAIVA, Adriano Martins de. Sindicalismo e direito de greve dos servidores públicos: aplicação da Convenção no 151 da OIT na regulamentação do inciso VII do art. 37 da CF/88. Revista do Tribunal Superior do Trabalho, Brasília, v. 78, n. 4, p. $17-$ 32, out./dez. 2012.

PINTO, José Augusto Rodrigues. Direito Sindical e Coletivo do Trabalho. São Paulo: LTr, 1998.

PIOVESAN, Flávia. Direitos humanos e o Direito Constitucional internacional. 14. ed. São Paulo: Saraiva, 2013.

RESENDE, Renato de Sousa. Negociação coletiva de servidor público. São Paulo: LTr, 2012. 
REZEK, José Francisco. Direito internacional público: curso elementar. 8. ed. São Paulo: Saraiva, 2000.

RODRIGUEZ, José Rodrigo. Dogmática da liberdade sindical: direito, política, globalização. Rio de Janeiro: Renovar, 2003.

SANTOS, Boaventura de Sousa. Democratizar a democracia: os caminhos da democracia participativa. 4. ed. Rio de Janeiro: Civilização Brasileira, 2009.

SANTOS, Enoque Ribeiro dos. Negociação coletiva de trabalho nos setores público e privado. São Paulo: LTr, 2015.

SCOGNAMIGLIO, Renato. Diritto del lavoro. 2. ed. Bari: Laterza, 2005.

SILVESTRIN, Edilene Freccia. Estudo comparativo das negociações coletivas realizadas junto às categorias dos servidores do Ministério do Trabalho e Emprego (MTE) e do Instituto Nacional do Seguro Social (INSS). 2010. Monografia (Especialização em Negociação Coletiva) - Universidade Federal do Rio Grande do Sul, Porto Alegre, RS.

STOLL, Luciana Bullamah. Negociação coletiva no setor público. São Paulo: LTr, 2007.

VALTICOS, Nicolas. Derecho Internacional del Trabajo. Trad. José Maria Treviño. Madrid: Tecnos, 1977.

Recebido em: 11 de janeiro de 2016 Aceito em: 25 de fevereiro de 2016 